\title{
Substance P Antagonists as a Therapeutic Approach to Improving Outcome Following Traumatic Brain Injury
}

\author{
Robert Vink and Corinna van den Heuvel \\ School of Medical Sciences, University of Adelaide, Adelaide, South Australia, Australia, 5005
}

\begin{abstract}
Summary: Although a number of secondary injury factors are known to contribute to the development of morphological injury and functional deficits following traumatic brain injury, accumulating evidence has suggested that neuropeptides, and in particular substance $\mathrm{P}$, may play a critical role. Substance $\mathrm{P}$ is released early following acute injury to the CNS as part of a neurogenic inflammatory response. In so doing, it facilitates an increase in the permeability of the bloodbrain barrier and the development of vasogenic edema. At the cellular level, substance $\mathrm{P}$ has been shown to directly result in neuronal cell death; functionally, substance $\mathrm{P}$ has
\end{abstract}

been implicated in learning and memory, mood and anxiety, stress mechanisms, emotion-processing, migraine, emesis, pain, and seizures, all of which may be adversely affected after brain injury. Inhibition of post-traumatic substance $P$ activity, either by preventing release or by antagonism of the neurokinin-1 receptor, has consistently resulted in a profound decrease in development of edema and marked improvements in functional outcome. This review summarizes the current evidence supporting a role for substance $\mathrm{P}$ in acute brain injury. Key Words: Neurotrauma, inflammation, edema, substance P, tachykinins.

\section{INTRODUCTION}

Traumatic brain injury (TBI) is the leading cause of death and disability in people under 40 years of age in developed countries. ${ }^{1}$ Although the costs for treatment, rehabilitation, and care of such individuals is measured in billion of dollars annually, no effective treatment currently exists. Brain injury results in the development of neurologic deficits through two main mechanisms, comprising primary and secondary events. Primary events are made up of the mechanical processes that occur at the time of the trauma, including tissue shearing, laceration, and stretching of nerve fibers. ${ }^{2}$ Preventive measures such as helmets, airbags, and seatbelts are the only interventions that can prevent or attenuate these primary events. In contrast, secondary injury evolves over minutes to days and even months after the initial event and is made up of delayed biochemical and physiological factors that are initiated by the primary event. These secondary injury factors are thought to account for much of the morbidity following brain injury, ${ }^{3}$ and their delayed nature presents opportunities for interventional pharmacology

Address correspondence and reprint requests to: Robert Vink, Ph.D., School of Medical Sciences, The University of Adelaide, SA 5005, Australia. E-mail: Robert.Vink@adelaide.edu.au. to prevent further injury and improve outcome. Accordingly, a significant research effort has been directed at identifying secondary injury factors and then developing novel therapies that may attenuate, or even prevent, their action.

Secondary injury factors identified to date include release of neurotransmitters (such as excitatory amino acids), ion changes, calpain activation, oxidative stress, blood-brain barrier (BBB) disruption, edema, and bioenergetic failure. ${ }^{2}$ Of these, profound edema has been clearly associated with mortality following severe TBI, as well as in the development of significant morbidity in up to $50 \%$ of surviving TBI patients. ${ }^{4}$ It is widely accepted that the development of edema has adverse consequences on outcome through effects on intracranial pressure (ICP). ${ }^{5}$ Current protocols for the management of elevated ICP include induction of hyperventilation or hypothermia, pharmacological regimens such as administration of diuretics or hyperosmotic agents, or surgical procedures such as drainage of CSF and decompressive craniectomy. ${ }^{6}$ Unfortunately, these interventions have essentially been inadequate, largely because they target the end-product of edema formation and not the fundamental issue of what specific mechanisms are associated with its development. Recent studies have suggested that neuropeptides, and in particular substance P (SP), may 
play a critical role in edema formation through actions at the level of the BBB. ${ }^{7,8}$ This alternative mechanistic approach to the management of post-traumatic edema and elevated ICP potentially offers a number of exciting opportunities.

\section{KININS AND SUBSTANCE P}

Substance P is a member of the tachykinin family of kinins. Kinins are a group of peptide mediators that have proinflammatory actions, some of which are mediated via the vasculature where they cause vasodilation and increased vascular permeability. The tachykinins, including SP, calcitonin gene-related peptide (CGRP), and neurokinin A, share specific amino acid sequences that allow them to be sorted into the tachykinin family. This family of compounds represents one of the largest peptide families described in animals. ${ }^{9}$ Substance $P$ was first identified as a crude extract with potent hypotensive and smooth muscle contractile properties isolated from equine brain..$^{10}$ It was identified in high concentrations in the dorsal root of the spinal cord, leading to the proposal that it is a neuronal sensory transmitter associated with pain transmission. ${ }^{11}$ Today, it is accepted that SP is released from both central and peripheral endings of sensory neurons and functions as a neurotransmitter. ${ }^{12}$ Its release, along with that of the other tachykinins, produces effects via tachykinin receptors, thereby playing a significant role in the neural component of inflammation known as neurogenic inflammation (discussed in the next section).

The other distinct family of kinins, the bradykinins, is formed from the cleavage of the plasma globulin kininogen, by plasma and tissue proteases known as kallikreins. The active peptides formed by this proteolytic cleavage are bradykinin and kallidin (lysyl bradykinin), and these kinins produce their effects through two subtypes of bradykinin receptors, $\mathrm{B}_{1}$ and $\mathrm{B}_{2}$. Bradykinin receptor antagonists have been shown to improve neurological outcome following TBI, ${ }^{13}$ even when administered up to $4 \mathrm{~h}$ post trauma. This neuroprotection is thought to be mediated, in part, by attenuating production of inducible nitric oxide synthase (iNOS) and prostaglandin E2 ${ }^{14}$ as well as edema formation ${ }^{13}$ and increases in ICP. ${ }^{15,16}$ An anti-inflammatory component has also been suggested, ${ }^{17}$ as well as inhibitory effects on reactive oxygen species generation. ${ }^{18}$ There is also evidence, however, to suggest that bradykinin itself may have glial cell-mediated neuroprotective and anti-inflammatory effects in the CNS, induced via attenuation of cytokine release from activated microglia, as well as by upregulation of neurotrophic factor production in astrocytes. ${ }^{19}$

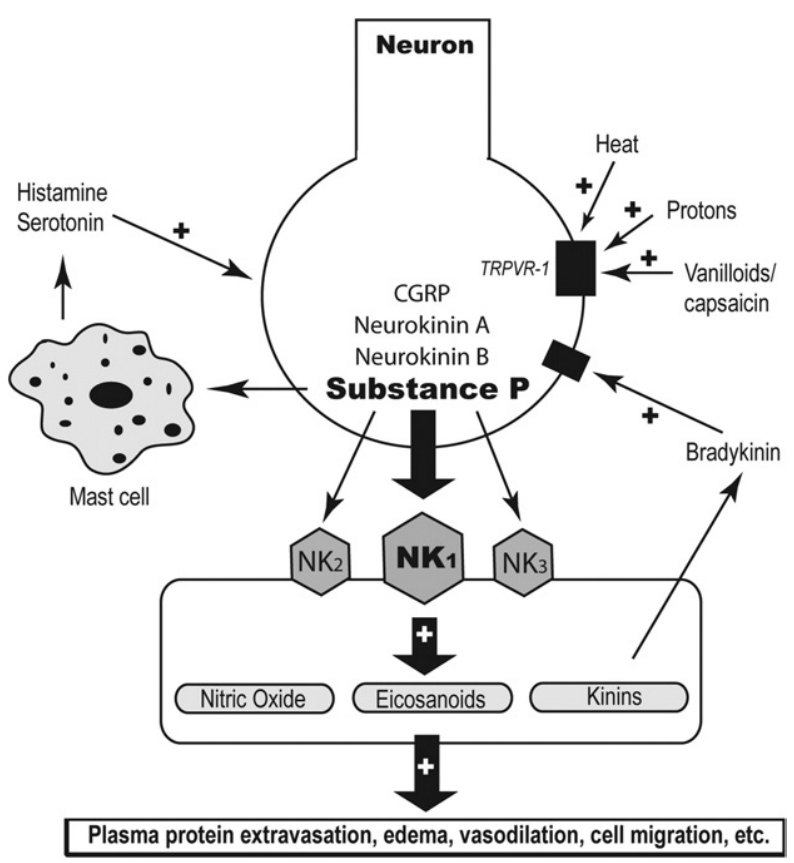

FIG. 1. Schematic of neurogenic inflammation demonstrating how the release of neuropeptides, and particularly of substance $\mathrm{P}$, is associated with the development of vascular permeability and edema formation. CGRP = calcitonin gene-related peptide; $\mathrm{NK}=$ neurokinin receptor; TRPVR $=$ transient receptor potential vanilloid receptor.

\section{NEUROGENIC INFLAMMATION}

Originally described as vasodilation of lower limb vessels following stimulation of the dorsal root ganglia, ${ }^{20}$ the concept of neurogenic inflammation (FIG. 1) has evolved to encompass vasodilation, plasma extravasation, and neuronal hypersensitivity caused by the release of neuropeptides from sensory neurons. ${ }^{21}$ Several neuropeptides have been implicated in this process, with CGRP identified as being associated with the vasodilation of arterioles and SP being thought to enhance plasma protein extravasation as well as leukocyte adhesion to endothelial cells in postcapillary venules. ${ }^{22} \mathrm{Ce}$ rebral blood vessels are surrounded by a dense supply of sensory neurons, as are virtually all blood vessels of the body, and these fibers contain both CGRP and SP. Any release of the neuropeptides around the cerebral vasculature would initiate neurogenic inflammation, a concept supported by the fact that neuropeptides are a therapeutic target to reduce vascular permeability in migraine. ${ }^{23}$ Following TBI, both enhanced vascular permeability of the BBB and cerebral vasodilation would potentially contribute to an increase in ICP.

Peptide-containing primary sensory neurons are characterized by their unique sensitivity to capsaicin, the pungent ingredient found in capsicum peppers. ${ }^{24}$ The transient receptor potential vanilloid receptor-1 (TRPVR1) is the site of binding by capsaicin, ${ }^{25}$ and this receptor has been identified as a nonselective cation channel whose endog- 
enous stimulants include heat $\left(>43^{\circ} \mathrm{C}\right)$ and protons (FIG. 1). Some primary sensory neurons are selectively stimulated by capsaicin; at higher concentrations, capsaicin kills these neurons, blocking the genesis of subsequent neurogenic inflammatory responses. ${ }^{24}$ These neurons are defined as capsaicin-sensitive, because of the specific excitatory-desensitization effect of capsaicin. ${ }^{26}$

\section{EDEMA}

A number of excellent reviews focusing on edema have been recently published, ${ }^{27,28}$ and the present discussion will focus on how neurogenic inflammation may contribute to the development of edema and elevated ICP following TBI. The association between profound edema formation and adverse outcomes following TBI has been recognized for quite some time, ${ }^{5}$ although the specific mechanisms associated with such cerebral edema formation remain largely unknown. Two major forms of edema have been described. Vasogenic edema is caused by the accumulation of extracellular fluid initiated via breakdown of the BBB and the diffusion of water down the osmotic gradient created by the influx of plasma proteins into the tissue. Cytotoxic, or cellular, edema is the shift of fluid from the extracellular compartment to the intracellular compartment, usually in response to an osmotic gradient created by the influx of ions into the cell. Notably, the shift of water from one compartment to another (extracellular to intracellular) does not result in any increase in brain water content, but rather a shift in its distribution. Without additional brain water content, increases in ICP would not be expected. In contrast, fluid derived from the vascular compartment (vasogenic edema) would result in additional brain water volume and would therefore manifest as an increase in ICP.

Recent evidence suggests that, although the BBB is permeable to larger molecules (plasma proteins) for only 4 to $6 \mathrm{~h}$ after TBI, it remains permeable to smaller molecules for at least 4 days after trauma. ${ }^{29}$ Thus, increased BBB permeability would be permissive for vasogenic edema formation for at least 4 days after trauma, coincident with the time frame of maximal edema formation after clinical TBI. Although cytotoxic edema is thought to be the predominant form of edema over this period, ${ }^{30}$ the movement of water across a permeable BBB would still be necessary to drive any net increase in brain water content, and therefore any increase in ICP. Moreover, any vasogenic edema would actually be permissive for cytotoxic edema formation. ${ }^{31}$

An increase in ICP may lead to a decrease in tissue perfusion, localized hypoxia and ischemia, further cytotoxic or vasogenic edema formation, and, in severe cases, brain herniation and death. It is therefore of paramount importance that the development of edema is inhibited following TBI. Although a number of studies have in- vestigated the role of classical inflammation in edema formation following TBI, ${ }^{32,33}$ to date few studies have examined the role of neurogenic inflammation. Nimmo et al. ${ }^{7}$ were among the first to do so, by demonstrating that chronic administration of capsaicin prior to TBI significantly attenuated BBB opening, edema formation, and the development of both motor and cognitive deficits. Chronic capsaicin administration is thought to transiently deplete sensory neuropeptides through persistent activation of the vanilloid receptor and continued release of the neuropeptides until the point of depletion. These authors ${ }^{7}$ also demonstrated that induction of injury during the active phase of neurogenic inflammation (immediately after capsaicin treatment) resulted in a $100 \%$ mortality, suggesting that ongoing neurogenic inflammation at the time of TBI is highly deleterious to outcome.

Although the Nimmo et al. ${ }^{7}$ study clearly demonstrated a role for neurogenic inflammation in TBI, the identification of which neuropeptide is primarily involved in increased BBB permeability and edema formation was not established. The identification of SP as the key neuropeptide in this process was subsequently reported by Donkin et al. ${ }^{8}$ On the basis of previous work demonstrating that capsaicin sensitivity in peripheral edema was most closely associated with $\mathrm{SP},{ }^{34-36}$ these authors demonstrated that TBI results in elevated perivascular SP immunoreactivity, which is associated with enhanced vascular permeability and subsequent edema formation. Such increases in perivascular SP immunoreactivity were also reported by the same investigators in a separate study of mild concussive head injury, ${ }^{37}$ with the authors suggesting that the observed increase in SP may be associated with the mild cognitive deficits observed at this severity of injury.

These experimental findings were confirmed in subsequent studies in human TBI, ${ }^{38}$ examining SP immunoreactivity in patients who had sustained traumatic head injuries, had died within 1 week, and had undergone post-mortem and detailed neuropathological examination. The neuropathological examination demonstrated a heterogeneous mixture of different cellular lesions including contusions and acute subdural hematomas. Elevated SP immunoreactivity was shown in cortical microvasculature $^{38}$ and was localized to perivascular neurons (FIG. 2), suggesting that injury to the neuron may result in localized release of the neuropeptide and an associated increase in BBB permeability and edema formation. Although SP has been recognized as primarily associated with increased vascular permeability, SP is stored and coreleased from sensory nerve endings with CGRP, a potent endogenous vasodilator that potentiates edema formation when in the presence of mediators of increased vascular permeability, such as SP. ${ }^{9,39}$ Thus, their combined release would facilitate a profound edema response. It is therefore reasonable to propose that antag- 

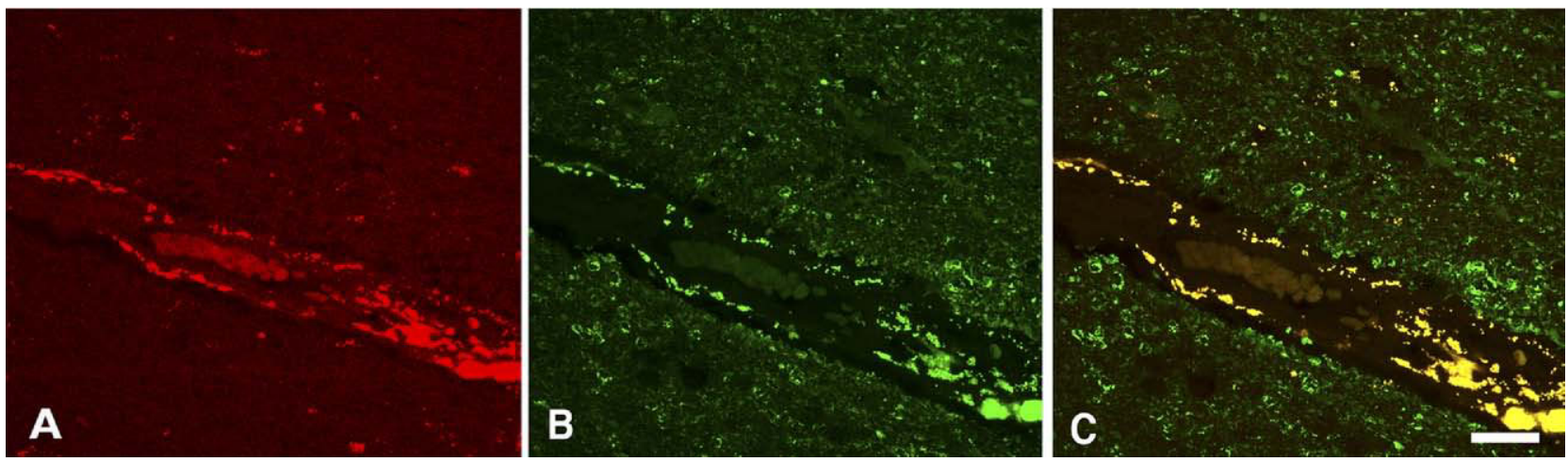

FIG. 2. Example of colocalization of substance $P$ with neuronal PGP 9.5 in a human cortical venule demonstrating that substance $P$ is associated with perivascular neurons: (A) neuronal PGP 9.5, red; (B) substance P, green; and (C) their colocalization, yellow. In this study, patients had sustained head injuries, had died within 1 week, and had undergone post-mortem and detailed neuropathological examination demonstrating a heterogeneous mixture of different cellular lesions, including contusions and acute subdural hematomas. The cerebral cortex was sampled directly beneath existing acute subdural hematomas or in proximity to contusions. Scale bar: $20 \mu \mathrm{m}$.

onists acting on SP receptors, and in particular the neurokinin-1 $\left(\mathrm{NK}_{1}\right)$ receptor, ${ }^{40}$ may be beneficial in the management of post-traumatic edema formation and elevated ICP.

\section{ACUTE CNS INJURY}

Relatively few studies have demonstrated that neurogenic inflammation plays a role in TBI, although a number of reports have supported a role for SP in other forms of acute CNS injury. Significant increases in SP have been demonstrated following peripheral nerve injury, ${ }^{41}$ traumatic spinal cord injury, ${ }^{42}$ and, more recently, in vitro studies of brain endothelium stimulation. ${ }^{43}$ In ischemia, enhanced SP immunoreactivity has been shown in the cerebral venous endothelium as well as in GABAergic interneurons around regions of infarction. ${ }^{44}$ Our own studies of transient brain ischemia have shown elevated perivascular SP immunoreactivity in injured tissue, which was associated with a significant increase in BBB permeability and edema formation. ${ }^{45}$ Notably, the change in perivascular SP immunoreactivity was observed only in transient ischemia and not in permanent ischemia, suggesting that reperfusion is necessary to induce neurogenic inflammation after ischemia.

Nonetheless, serum levels of SP measured in humans following both transient ischemic attack and complete stroke have been found to be significantly elevated, compared with controls, ${ }^{46}$ although one cannot exclude the possibility that some reperfusion may have occurred in those patients classified as complete stroke. Receptor binding sites for SP have also been shown to increase on glia after neuronal injury, ${ }^{47}$ suggesting that the neuropeptide may regulate the glial response to injury. Subsequent studies have confirmed that SP receptors are expressed on astrocytes after injury and may therefore be linked to their transformation to reactive astrocytes; ${ }^{48}$ this increase was not observed in undamaged areas. Fi- nally, high levels of SP in CNS tissue have also been shown to directly result in neuronal nonapoptotic programmed cell death ${ }^{49}$ and have been implicated in learning and memory, mood and anxiety, stress mechanisms, and emotion processing, as well as in the pathophysiology of epilepsy. ${ }^{50,51}$

\section{NK $_{1}$ RECEPTOR ANTAGONISTS}

The concept that tachykinin receptor antagonists may have therapeutic applications has been suggested over a number of years by various research groups. The idea was first raised in 1979 in relation to the effects of SP agonists in the guinea pig ileum. ${ }^{52}$ In 1981 , Folkers et al. ${ }^{53}$ proposed a chemical design of SP antagonists. Engberg et al. ${ }^{54}$ then developed the first synthetic peptide antagonist for use in the CNS, before the first nonpeptide SP antagonist was developed 10 years later by Snider et al. ${ }^{55}$ in the form of CP-96,345, a potent and highly selective antagonist of the $\mathrm{NK}_{1}$ receptor. The next generation of $\mathrm{NK}_{1}$ antagonists were the highly potent $N$ acetyl-L-tryptophan benzyl esters, ${ }^{56}$ which were subsequently used as a starting point to identify high-affinity SP receptor antagonists with improved in vivo activity. In vivo, the efficacy of SP antagonists has now been demonstrated in the treatment of experimental depression and emesis. ${ }^{57}$ Indeed, the $\mathrm{NK}_{1}$ receptor antagonists were able to decrease experimental anxiety ${ }^{58}$ and depression with fewer side effects than other drugs used for this purpose. ${ }^{9}$ This observation has now been translated to the clinical arena, with the SP antagonist MK-0869 being successfully used in the treatment of clinical depression and anxiety. ${ }^{59} \mathrm{NK}_{1}$ receptor antagonists have also been tested in dental pain, osteoarthritis, neuropathic pain and migraine; however, no analgesic effects have been reported to date. ${ }^{40}$

In terms of acute CNS injury, few studies using $\mathrm{NK}_{1}$ receptor antagonists have been reported, although those 
that have appeared support a central role for SP in injury pathogenesis. Donkin et al. ${ }^{8}$ demonstrated in a rodent model of diffuse TBI that administration of the $\mathrm{NK}_{1}$ antagonist, $N$-acetyl-L-tryptophan, at $30 \mathrm{~min}$ after trauma induction resulted in a marked attenuation of BBB permeability and subsequent edema formation over the ensuing $5 \mathrm{~h}$. This attenuation was associated with a significant improvement in both motor and cognitive outcome in the animals as recorded over the first week after injury. Notably, the $\mathrm{NK}_{1}$ antagonist also increased brain free $\mathrm{Mg}^{2+}$ concentration after trauma, ${ }^{60}$ implying that some of the observed neuroprotection conferred by the $\mathrm{NK}_{1}$ antagonist may be mediated by $\mathrm{Mg}^{2+}$.

Magnesium has been reported to be an important secondary injury factor following TBI. Decline in $\mathrm{Mg}^{2+}$ has been associated with adverse outcomes, and administration of $\mathrm{Mg}^{2+}$ salts improves cellular, biochemical, and functional outcomes after TBI. ${ }^{61-63}$ In a rodent focal ischemia model, the $\mathrm{NK}_{1}$ receptor antagonist SR140333 also significantly reduced infarct volume, implying that SP might play a role in exacerbating ischemic damage. ${ }^{64}$ Turner and Vink ${ }^{65}$ subsequently demonstrated in a rat transient middle cerebral artery occlusion model that $\mathrm{NK}_{1}$ receptor antagonists given at $4 \mathrm{~h}$ after induction of ischemia can reduce BBB permeability and brain edema. There was also an associated improvement in functional deficits as measured using a battery of neurological outcome tests, although no reduction in lesion volume was reported. Whether this indicates that SP antagonists might be beneficial to functional outcome by enhancing synaptic connectivity around the lesion is the subject of further investigation. Thus, SP has been reported to play a critical role in acute injuries to the CNS, be they traumatic or ischemic, with the $\mathrm{NK}_{1}$ antagonists demonstrating utility for reduction in BBB permeability, edema formation, lesion volumes as well as improvement in functional outcome.

Studies in other organs also support the beneficial effects of the $\mathrm{NK}_{1}$ antagonists reported following injury to the CNS. For example, post-ischemic blockade of tachykinin receptors following ischemia and reperfusion of the superior mesenteric artery in the rat have been shown to inhibit vascular permeability, neutrophil recruitment, intestinal hemorrhage and neutropenia. ${ }^{66} \mathrm{Sim}-$ ilarly, SP antagonists reduce post-ischemic myocardial injury in rats with dietary $\mathrm{Mg}$ deficiency, ${ }^{67}$ with the authors suggesting that SP may play an early critical role in inflammatory or prooxidant responses following ischemia. This finding is of particular interest to TBI, in that traumatic injury has been shown to produce sustained decline in intracellular free $\mathrm{Mg}^{2+}$ concentration, ${ }^{68}$ and it is possible that the detrimental effects of $\mathrm{Mg}^{2+}$ deficiency or decline may be mediated, in part, by the increases in SP. In guinea pig skin, administration of the $\mathrm{NK}_{1}$ receptor antagonist RP 67580 was shown to atten- uate SP induced edema formation and white blood cell accumulation. ${ }^{69}$ Finally, in vitro studies of endothelial injury have demonstrated that $\mathrm{NK}_{1}$ antagonists neutralize increased BBB permeability, attenuate upregulation of MHC-II molecules, reduce expression of ICAM-1, and prevent associated cell morphological changes. ${ }^{43}$

Alongside studies with the $\mathrm{NK}_{1}$ antagonists, which have been useful in establishing a role for SP and neurogenic inflammation in brain injury, an alternative approach to inhibition of central neurogenic inflammation is neuropeptide depletion. This can be accomplished by chronic preinjury administration of the vanilloid receptor agonist capsaicin, which stimulates the release of neuropeptides from the sensory nerve terminals (FIG. 1). Repeated administration of the compound ultimately results in the depletion of the presynaptic stores of neuropeptides and thus an inhibition of neurogenic inflammation. ${ }^{70}$ Using this approach, Nimmo et al. ${ }^{7}$ demonstrated that neuropeptide-depletion prior to induction of TBI attenuated post-traumatic BBB permeability and vasogenic edema formation, and resulted in an improvement in motor and cognitive function after TBI. Although the findings were not of direct therapeutic relevance, the authors concluded that inhibition of neurogenic inflammation could present a novel approach to the treatment of TBI.

\section{CONCLUSION}

The role of classical inflammation in acute brain injury has been appreciated for quite some time, but until recently there has been little recognition of the potential role that neurogenic inflammation may play in the secondary injury process associated with TBI. Given the dense supply of sensory nerve fibers that surround cerebral blood vessels, it is perhaps not surprising that these fibers facilitate an active neurogenic response to injury. The result is an increase in perivascular SP that, along with other neuropeptides, facilitates increased vascular permeability, vasodilation, and edema formation. Notably, inhibition of the post-traumatic neurogenic inflammation through either inhibition of neuropeptide release or by administration of a $\mathrm{NK}_{1}$ receptor antagonist, prevents $\mathrm{BBB}$ opening and inhibits edema formation. This attenuation of neurogenic inflammation is associated with an improvement in functional outcome, including both motor and cognitive parameters. Because $\mathrm{NK}_{1}$ antagonists have also been shown to positively affect anxiety and depression, stress mechanisms, emotion-processing, emesis, and seizures, all of which are commonly encountered after TBI, these compounds offer a novel and exciting prospect for use in acute brain injury.

Acknowledgments: R.V. is supported by the Neurosurgical Research Foundation (North Adelaide, SA, Australia). 


\section{REFERENCES}

1. Tagliaferri F, Compagnone C, Korsic M, Servadei F, Kraus J. A systematic review of brain injury epidemiology in Europe. Acta Neurochir (Wien) 2006;148:255-268.

2. Blumbergs PC, Reilly PL, Vink R. Trauma. In: Love S, Louis DN, Ellison DW, editors. Greenfield's neuropathology. 8th ed. London: Hodder Arnold, 2008:733-832.

3. McIntosh TK, Smith DH, Meaney DF, Kotapka MJ, Gennarelli TA, Graham DI. Neuropathological sequelae of traumatic brain injury: relationship to neurochemical and biomechanical mechanisms. Lab Invest 1996;74:315-342.

4. Feickert HJ, Drommer S, Heyer R. Severe head injury in children: impact of risk factors on outcome. J Trauma 1999;47:33-38.

5. Marmarou A, Fatouros PP, Barzó P, et al. Contribution of edema and cerebral blood volume to traumatic brain swelling in headinjured patients. J Neurosurg 2000;93:183-193.

6. Brain Trauma Foundation; American Association of Neurological Surgeons, Joint Section on Neurotrauma and Critical Care. Initial management. J Neurotrauma 2000;17:463-469.

7. Nimmo AJ, Cernak I, Heath DL, Hu X, Bennett CJ, Vink R. Neurogenic inflammation is associated with development of edema and functional deficits following traumatic brain injury in rats. Neuropeptides 2004;38:40-47.

8. Donkin JJ, Nimmo AJ, Cernak I, Blumbergs PC, Vink R. A critical role for substance $\mathrm{P}$ in the development of traumatic brain edema. J Cereb Blood Flow Metab 2009;29:1388-1398.

9. Severini C, Improta G, Falconieri-Erspamer G, Salvadori S, Erspamer V. The tachykinin peptide family. Pharmacol Rev 2002;54: $285-322$.

10. von Euler US, Gaddum JH. An unidentified depressor substance in certain tissue extracts. J Physiol 1931;72:74-87.

11. Lembeck F. Central transmission of afferent impulses: III. Incidence and significance of the substance $\mathrm{P}$ in the dorsal roots of the spinal cord [In German]. Naunyn Schmiedebergs Arch Exp Pathol Pharmakol 1953;219:197-213.

12. Otsuka M, Yoshioka K. Neurotransmitter functions of mammalian tachykinins. Physiol Rev 1993;73:229-308.

13. Kaplanski J, Pruneau D, Asa I, et al. LF $16-0687$ Ms, a bradykinin $\mathrm{B}_{2}$ receptor antagonist, reduces brain edema and improves longterm neurological function recovery after closed head trauma in rats. J Neurotrauma 2002;19:953-964.

14. Kaplanski J, Asa I, Artru AA, et al. LF 16-0687 Ms, a new bradykinin $B_{2}$ receptor antagonist, decreases ex vivo brain tissue prostaglandin E2 synthesis after closed head trauma in rats. Resuscitation 2003;56:207-213.

15. Marmarou A, Nichols J, Burgess J, et al. Effects of the bradykinin antagonist Bradycor (deltibant, CP-1027) in severe traumatic brain injury: results of a multi-center, randomized, placebo-controlled trial. J Neurotrauma 1999;16:431-444.

16. Zweckberger K, Plesnila N. Anatibant, a selective non-peptide bradykinin $\mathrm{B}_{2}$ receptor antagonist, reduces intracranial hypertension and histopathological damage after experimental traumatic brain injury. Neurosci Lett 2009;454:115-117.

17. Rodi D, Couture R, Ongali B, Simonato M. Targeting kinin receptors for the treatment of neurological diseases. Curr Pharm Des 2005;11:1313-1326.

18. Chiang WC, Chien CT, Lin WW, et al. Early activation of bradykinin $B_{2}$ receptor aggravates reactive oxygen species generation and renal damage in ischemia/reperfusion injury. Free Radic Biol Med 2006;41:1304-1314.

19. Noda M, Kariura Y, Pannasch U, et al. Neuroprotective role of bradykinin because of the attenuation of pro-inflammatory cytokine release from activated microglia. J Neurochem 2007;101: 397-410.

20. Bayliss WM. On the origin from the spinal cord of the vaso-dilator fibres of the hind-limb, and on the nature of these fibres. J Physiol 1901;26:173-209.

21. Black PH. Stress and the inflammatory response: a review of neurogenic inflammation. Brain Behav Immun 2002;16:622-653.

22. Geppetti P, Bertrand C, Ricciardolo FL, Nadel JA. New aspects on the role of kinins in neurogenic inflammation. Can J Physiol Pharmacol 1995;73:843-847.
23. Ferrari MD. Migraine. Lancet 1998;351:1043-1051.

24. Szallasi A, Blumberg PM. Vanilloid (capsaicin) receptors and mechanisms. Pharmacol Rev 1999;51:159-212.

25. Caterina MJ, Schumacher MA, Tominaga M, et al. The capsaicin receptor: a heat-activated ion channel in the pain pathway. Nature 1997;389:816-824.

26. Szolcsányi J, Mózsik G. Effects of capsaicin on the development of gastric mucosal damage by different necrotizing agents and of gastric cytoprotection by PGI2 atropine and cimetidine on rats. Acta Physiol Hung 1984;64:287-291.

27. Marmarou A. A review of progress in understanding the pathophysiology and treatment of brain edema. Neurosurg Focus 2007; 22(5):E1.

28. Nag S, Manias JL, Stewart DJ. Pathology and new players in the pathogenesis of brain edema. Acta Neuropathol 2009;118:197217.

29. Habgood MD, Bye N, Dziegielewska KM, et al. Changes in bloodbrain barrier permeability to large and small molecules following traumatic brain injury in mice. Eur J Neurosci 2007;25:231-238.

30. Marmarou A, Portella G, Barzo P, et al. Distinguishing between cellular and vasogenic edema in head injured patients with focal lesions using magnetic resonance imaging. Acta Neurochir Suppl (Wien) 2000;76:349-351.

31. Beaumont A, Marmarou A, Hayasaki K, et al. The permissive nature of blood brain barrier (BBB) opening in edema formation following traumatic brain injury. Acta Neurochir Suppl (Wien) 2000;76:125-129.

32. Arvin B, Neville LF, Barone FC, Feuerstein GZ. The role of inflammation and cytokines in brain injury. Neurosci Biobehav Rev 1996;20:445-452

33. Morganti-Kossmann MC, Rancan M, Stahel PF, Kossmann T. Inflammatory response in acute traumatic brain injury: a doubleedged sword. Curr Opin Crit Care 2002;8:101-105.

34. Saria A. Substance P in sensory nerve fibres contributes to the development of oedema in the rat hind paw after thermal injury. Br J Pharmacol 1984;82:217-222.

35. Yonehara N, Shibutani T, Inoki R. Contribution of substance $P$ to heat-induced edema in rat paw. J Pharmacol Exp Ther 1987;242: 1071-1076.

36. De AK, Ghosh JJ. Inflammatory responses induced by substance $\mathrm{P}$ in rat paw. Indian J Exp Biol 1990;28:946-948.

37. Donkin JJ, Cernak I, Rodgers KM, Vink R. Mild concussive head injury results in increased brain substance P immunoreactivity. In: 7th International Neurotrauma Symposium. Bologna: Medimond International Proceedings, 2004:75-78.

38. Zacest AC, Vink R, Manavis J, Sarvestani GT, Blumbergs PC. Substance P immunoreactivity increases following human traumatic brain injury. Acta Neurochir Suppl (Wien) 2009;106:211216.

39. Brain SD, Williams TJ. Inflammatory oedema induced by synergism between calcitonin gene-related peptide (CGRP) and mediators of increased vascular permeability. Br J Pharmacol 1985;86: 855-860.

40. Hökfelt T, Pernow B, Wahren J. Substance P: a pioneer amongst neuropeptides. J Intern Med 2001;249:27-40.

41. Malcangio M, Ramer MS, Jones MG, McMahon SB. Abnormal substance $\mathrm{P}$ release from the spinal cord following injury to primary sensory neurons. Eur J Neurosci 2000;12:397-399.

42. Sharma HS, Nyberg F, Olsson Y, Dey PK. Alteration of substance $\mathrm{P}$ after trauma to the spinal cord: an experimental study in the rat. Neuroscience 1990;38:205-212.

43. Annunziata P, Cioni C, Santonini R, Paccagnini E. Substance P antagonist blocks leakage and reduces activation of cytokine-stimulated rat brain endothelium. J Neuroimmunol 2002;131:41-49.

44. Stumm R, Culmsee C, Schafer MK, Krieglstein J, Weihe E. Adaptive plasticity in tachykinin and tachykinin receptor expression after focal cerebral ischemia is differentially linked to GABAergic and glutamatergic cerebrocortical circuits and cerebrovenular endothelium. J Neurosci 2001;21:798-811.

45. Turner RJ, Blumbergs PC, Sims NR, Helps SC, Rodgers KM, Vink R. Increased substance $\mathrm{P}$ immunoreactivity and edema formation following reversible ischemic stroke. Acta Neurochir Suppl (Wien) 2006;96:263-266. 
46. Bruno G, Tega F, Bruno A, et al. The role of substance $P$ in cerebral ischemia. Int J Immunopathol Pharmacol 2003;16:67-72.

47. Mantyh PW, Johnson DJ, Boehmer CG, et al. Substance P receptor binding sites are expressed by glia in vivo after neuronal injury. Proc Natl Acad Sci U S A 1989;86:5193-5197.

48. Lin RC. Reactive astrocytes express substance-P immunoreactivity in the adult forebrain after injury. Neuroreport 1995;7:310-312.

49. Castro-Obregón S, Rao RV, del Rio G, et al. Alternative, nonapoptotic programmed cell death: mediation by arrestin-2, ERK2 and Nur77. J Biol Chem 2004;279:17543-17553.

50. Alvaro G, Di Fabio R. Neurokinin 1 receptor antagonists: current prospects. Curr Opin Drug Discov Devel 2007;10:613-621.

51. Liu H, Mazarati AM, Katsumori H, Sankar R, Wasterlain CG. Substance $\mathrm{P}$ is expressed in hippocampal principal neurons during status epilepticus and plays a critical role in the maintenance of status epilepticus. Proc Natl Acad Sci U S A 1999;96:5286-5291.

52. Leban J, Rackur G, Yamaguchi I, et al. Synthesis of substance P analogs and agonistic and antagonistic activities. Acta Chem Scand B 1979;33:664-668.

53. Folkers K, Hörig J, Rosell S, Björkroth U. Chemical design of antagonists of substance P. Acta Physiol Scand 1981;111:505-506.

54. Engberg G, Svensson TH, Rosell S, Folkers K. A synthetic peptide as an antagonist of substance P. Nature 1981;293:222-223.

55. Snider RM, Longo KP, Drozda SE, Lowe JA 3rd, Leeman SE. Effect of CP-96,345, a nonpeptide substance P receptor antagonist, on salivation in rats. Proc Natl Acad Sci U S A 1991;88:1004210044.

56. MacLeod AM, Cascieri MA, Merchant KJ, et al. Synthesis and biological evaluation of NK1 antagonists derived from L-tryptophan. J Med Chem 1995;38:934-941.

57. Rupniak NM, Kramer MS. Discovery of the antidepressant and anti-emetic efficacy of substance P receptor (NK1) antagonists. Trends Pharmacol Sci 1999;20:485-490.

58. Santarelli L, Gobbi G, Debs PC, et al. Genetic and pharmacological disruption of neurokinin 1 receptor function decreases anxietyrelated behaviors and increases serotonergic function. Proc Natl Acad Sci U S A 2001;98:1912-1917.
59. Ranga K, Krishnan R. Clinical experience with substance P receptor (NK1) antagonists in depression. J Clin Psychiatry 2002;63 Suppl 11:25-29.

60. Vink R, Donkin JJ, Cruz MI, Nimmo AJ, Cernak I. A substance P antagonist increases brain intracellular free magnesium concentration after diffuse traumatic brain injury in rats. J Am Coll Nutr 2004;23:538S-540S.

61. Vink R. Nuclear magnetic resonance characterization of secondary mechanisms following traumatic brain injury. Mol Chem Neuropathol 1993;18:279-297.

62. Vink R, O'Connor CA, Nimmo AJ, Heath DL. Magnesium attenuates persistent functional deficits following diffuse traumatic brain injury in rats. Neurosci Lett 2003;336:41-44.

63. Vink R, Nimmo AJ. Multifunctional drugs for head injury. Neurotherapeutics 2009;6:28-42.

64. Yu Z, Cheng G, Huang X, Li K, Cao X. Neurokinin-1 receptor antagonist SR140333: a novel type of drug to treat cerebral ischemia. Neuroreport 1997;8:2117-2119.

65. Turner R, Vink R. Inhibition of neurogenic inflammation as a novel treatment for ischemic stroke. Drug News Perspect 2007;20: 221-226.

66. Souza DG, Mendonça VA, de A Castro MS, Poole S, Teixeira MM. Role of tachykinin NK receptors on the local and remote injuries following ischaemia and reperfusion of the superior mesenteric artery in the rat. Br J Pharmacol 2002;135:303-312.

67. Kramer JH, Phillips TM, Weglicki WB. Magnesium deficiency enhanced post-ischemic myocardial injury is reduced by substance P receptor blockade. J Cardiol 1997;29:97-110.

68. Heath DL, Vink R. Traumatic brain axonal injury produces sustained decline in intracellular free magnesium concentration. Brain Res 1996;738:150-153.

69. Campos MM, Calixto JB. Neurokinin mediation of edema and inflammation. Neuropeptides 2000;34:314-322.

70. Kashiba H, Ueda Y, Senba E. Systemic capsaicin in the adult rat differentially affects gene expression for neuropeptides and neurotrophin receptors in primary sensory neurons. Neuroscience 1997;76:299-312. 